Tropical Journal of Pharmaceutical Research April 2019; 18 (4): 869-875

ISSN: $1596-5996$ (print); 1596-9827 (electronic)

(C) Pharmacotherapy Group, Faculty of Pharmacy, University of Benin, Benin City, 300001 Nigeria.

\title{
Cost associated with hospitalization of non-adherent type 2 diabetes patients in a tertiary healthcare facility in Ibadan, Nigeria
}

\author{
Aduke Elizabeth Ipingbemi ${ }^{1 *}$, Wilson Oyekigho Erhun ${ }^{1,2}$ \\ ${ }^{1}$ Department of Clinical Pharmacy and Pharmacy Administration, University of Ibadan, Ibadan, ${ }^{2}$ Department of Clinical \\ Pharmacy and Pharmacy Administration, Obafemi Awolowo University, Ile-Ife, Nigeria
}

*For correspondence: Email: pharmaduke@yahoo.com; Tel: +234-8023635696

\begin{abstract}
Purpose: To estimate the cost of hospitalization associated with medication non-adherence among type 2 diabetes mellitus (T2DM) patients in a tertiary healthcare facility in Nigeria.

Methods: Three hundred and fifty-four (354) medical records of T2DM patients admitted into the medical wards from 2013 to 2015 were used for the study. Medical records with history of medication non-adherence (MNA) prior to hospitalization as indicated by physicians were included in the study. Direct medical costs associated with the management of the patients during hospitalization were measured using out-of-pocket payer perspective. Pearson product moment correlation coefficient was used to determine the relationship between the variables, with $p<0.05$ considered statistically significant.

Results: Among the 354 admitted patients, 226 (63.8 \%) had a record of MNA. The mean age was $57.5 y e a r s \pm 14.6$. The majority of the patients $(61.5 \%)$ were either petty traders or artisans/selfemployed. Duration of hospitalization increased with increase in number of comorbid disease (Pearson product moment correlation $r=0.13 p=0.05$ ). Total cost incurred during hospitalization was US\$146,669.3 (average, \$650.1), of which more than one quarter was cost of medications. Cost of management and cost of laboratory investigations increased with increase in the number of co-morbid diseases ( $r=0.24, p=0.00 ; r=0.2, p=0.02$, respectively). Cost of management also increased with increase in days of hospitalization $(r=0.2, p=0.00)$.

Conclusion: Cost of hospitalization related to non-adherence to medication is high among the studied population. There is need to work out strategies to enhance adherence among diabetes patients.
\end{abstract}

Keywords: Non-adherence, Cost, Management, Hospitalization, Co-morbid diseases

This is an Open Access article that uses a fund-ing model which does not charge readers or their institutions for access and distributed under the terms of the Creative Commons Attribution License (http://creativecommons.org/licenses/by/4.0) and the Budapest Open Access Initiative (http://www.budapestopenaccessinitiative.org/read), which permit unrestricted use, distribution, and reproduction in any medium, provided the original work is properly credited.

Tropical Journal of Pharmaceutical Research is indexed by Science Citation Index (SciSearch), Scopus, International Pharmaceutical Abstract, Chemical Abstracts, Embase, Index Copernicus, EBSCO, African Index Medicus, JournalSeek, Journal Citation Reports/Science Edition, Directory of Open Access Journals (DOAJ), African Journal Online, Bioline International, Open-J-Gate and Pharmacy Abstracts

\section{INTRODUCTION}

Diabetes mellitus (DM) is a group of chronic medical conditions in which there is derangement of metabolism in the body. It could occur when there is absolute or low insulin production or resistance to the produced insulin, resulting in a sustained hyperglycaemic state [1]. The persistent hyperglycaemia and associated complications requires intensive care and visit to 
healthcare facilities, which increases the cost of care of the disease.

Globally, about 285 million people were living with DM in 2010. This was projected to double by 2030 [2]. In Nigeria, there is no nation-wide survey or any research within Nigeria with current report on the prevalence of diabetes in the country. The last national survey of non-communicable diseases (NCDs), carried out in 1997, reported $2.2 \%$ as prevalence of diabetes in Nigeria [3]. However, the prevalence of T2DM has been high and is still increasing in Nigeria, with the country reported as having the highest burden of diabetes in Africa [4]. Globally, the number of patients with diabetes has been projected to double by 2050 [2]. Therefore, the prevalence of diabetes is high. This is a concern for both public health and public policy. Oral diabetes medications and insulin are the core agents for management of diabetes. However, about one-third of diabetic patients do not attain optimal benefit from the therapy due to medication non-adherence (MNA) [5].

Adherence with medication therapy is generally low among patients with chronic conditions such as diabetes [6]. In the United States, poor adherence to medication has been shown to lead to an estimate of 125,000 deaths annually and 33 to $69 \%$ of medication-related hospital admissions [7, 8]. Many studies have reported that MNA is associated with increase in inpatient admission, emergency department visit, and total diabetes-related cost $[6,9]$. Medication nonadherence (MNA) has been shown to cost $\$ 100$ to $\$ 300$ billion each year on avoidable hospitalization in the US when both direct and indirect costs are included, this represented 3 to $10 \%$ of total US healthcare costs [8].

In $2010,12 \%$ of the health expenditures and US\$ 1330 (ID 1478) per individual was anticipated to be spent on diabetes mellitus globally [10]. However, this expenditure was found to vary by age group, sex, region, and country's level of income [10]. Many factors can lead to poor medication adherence among patients. Nevertheless, high costs of medications and co-payments that some patients have to pay for medications prescribed for them have been shown to negatively effect adherence to medication [11].

The World Health Organisation claims that over the past decade, there was greater increase in the prevalence of diabetes in low- and middleincome countries than what was reported in highincome countries [12]. Past studies in Nigeria have been mainly on the burden of diabetes in the country $[13,14]$. Data on cost of hospitalization resulting from non-adherence to medication(s) among patients diagnosed with diabetes mellitus are scare. Therefore, this study estimated the cost associated with hospitalization among non-adherent T2DM patients in one of the largest tertiary healthcare institutions in southwestern Nigeria.

\section{METHODS}

This study involved collection of data from case notes of patients diagnosed with T2DM and admitted to the University College Hospital (UCH) Ibadan, Nigeria. They had a record of subjective assessment of the physician for nonadherence to medication as documented in their case notes at the point of admission (in 2013, 2014 and 2015) into the hospital.

\section{Study population}

Available information from the Record Department of $\mathrm{UCH}$ indicated that 354 patients were on admission during the 3-year period. Out of this figure, 226 had records of subjective assessment of physician for non-adherence to medication as documented in their case notes at the point of admission and were available for use for the study.

\section{Data collection}

The case notes of the patients admitted in the years 2013, 2014 and 2015 were retrieved from the Statistics Section of the Record Department in the University College Hospital (UCH). Each case note was well screened and anyone with a record of non-adherence to medication(s) as indicated by physician in the case note clerking was included in the study.

Three hundred and fifty-four (354) case notes were retrieved and 226 were found to have records of non-adherence to medication(s). The remaining 128 were those who had no record of non-adherence to therapy due to the fact that they were newly diagnosed cases and some others were admitted to the hospital as a result of other comorbid diseases but had good blood glucose control.

Data were retrieved from the case notes assessed for cost of non-adherence arising from cost of hospitalization. They included costs of investigations, medications, consumables, bed fee, oxygen use, procedures, physiotherapy services, dressings and of transportation. These were calculated as direct cost associated with 
their hospitalization resulting from nonadherence to medication(s).

The primary outcome variables were cost types (medications, diet, bed fee, laboratory investigations, procedures, use of other hospital facilities, and transportation fee) measured in the 2013, 2014 and 2015 USD exchange rate using the out-of-pocket perspective. Costs for each year were presented as cost for the population of patients admitted due to non-adherence to medication(s) before admission that year. Other variables included were age, sex, marital status, residence, and comorbidities.

The comorbidities included anaemia, stroke, heart failure, cardiovascular disease, hypertension, liver disease, diseases of the lung, renal failure (chronic and acute), peptic ulcer disease and bleeding; they were defined according to ICD-9 codes. The comorbidities were categorized as count of comorbidities, which was defined as 0 , (that is none), 1,2 , and 3 or more. This count has been reported to be more efficient [5].

The cost items for this study included direct medical cost and non-medical cost. Direct medical cost included cost of medications (diabetes medication, hypertension, comorbid diseases), cost of all laboratory investigations related to disease state, bed fee, procedures (amputation), cost of blood transfusion, dressings, use of oxygen, physiotherapist service, nursing services.

The cost of medication was calculated using unit dose of medication used and summing up total cost of medication used for the period of hospitalization. The cost for all the direct medical cost was based on hospital tariff of each year studied. The non-medical cost was cost of transportation (to and fro from the hospital) based on National Union of Road Transport Workers' (NURTW's) tariff in the state.

\section{Data analysis}

Data were entered into SPSS version 23 and analysed. Pearson product moment correlation coefficient was used to determine the relationship between variables, with $p<0.05$ considered statistically significant.

\section{Currency exchange rate applied}

1.0 US $\$$ was taken to be equivalent to a mean of Nigerian naira (\$)156.5 for 2013, 170.0 for 2014, and 189.0 for 2015 [16]. The mean exchange rate over the 3-year period was \#171.8 to US\$1.0.

\section{Ethical approval}

Ethical approval was received from the $\mathrm{UI} / \mathrm{UCH}$ Research Review Board on 14th April, 2015, with certification no. UI/UCH EC and registration no. NHREC/05/01/2008a. The international guideline for human studies used was the NIH guideline for human subject research protection. This guideline was borne in mind when collecting data retrospectively [15].

\section{RESULTS}

The total number of the available case notes of admitted patients primarily diagnosed with T2DM within the study period was 354 . Those with a record of non-adherence to medication(s) which resulted in their hospitalization were 226, which was $63.8 \%$ of the admitted patients. The number of patients admitted in each year with a record of non-adherence included: 83 (36.7\%), for 2015; 68 (30.1\%), for 2014; and 75 (33.2\%), for 2013. There were 115 (50.9\%) males and 111 (49.1 $\%)$ females. The patients had a mean age of 57.5 years (SD, 14.56) and an average duration of diabetes of 6.0 years (SD, 5.77). The majority $148(65.5 \%)$ had been diagnosed for $1-5$ years, $50(22.1 \%)$ for 6 - 10 years, and 28 (12.4\%) for $>10$ years. About $85(37.6 \%)$ lived outside the Ibadan metropolis, while 141 (62.4 \%) lived within the metropolis.

As for the number of days on admission: 114 patients $(50.4 \%)$ were admitted for 1 - 10 days; 90 (39.8\%) for $11-20$ days; and 22 (9.7\%) patients for $>20$ days. The mean duration of admission was 11.9 days (SD, 10.6) and mean $\mathrm{HbA} 1 \mathrm{c}$ among the patients was $10.45 \%$ (SD, $1.94 \%$.

Table 1: Occupation of patients

\begin{tabular}{lcc}
\hline Occupation & Frequency & Percent \\
\hline Petty trader & 62 & 27.4 \\
Self-employed & 40 & 17.6 \\
Retiree & 39 & 17.3 \\
Artisan & 37 & 16.4 \\
Civil servant & 30 & 13.3 \\
Unemployed & 18 & 8.0 \\
Total & $\mathbf{2 2 6}$ & $\mathbf{1 0 0 . 0}$ \\
\hline
\end{tabular}

With regard to reasons for non-adherence, the majority of the patients had a record of costrelated non-adherence $152(69.0 \%)$, and being tired of taken multiple drugs 46 (20.3\%), while $28(12.4 \%)$ had no record of reason for nonadherence to medication(s). 
Among this population, 101 (44.7\%) patients were being managed for T2DM and other comorbid conditions, while 125 (55.3\%) were both hypertensive and T2DM patients. Also, 32 $(14.2 \%)$ were National Health Insurance Scheme enrollees, while 194 (85.8 \%) were not and pay for the medical bills out of their pockets.

Table 2: Co-morbidity conditions presented by the patients and cost of management during their hospitalization

\begin{tabular}{|c|c|c|}
\hline Co-morbid condition & $\begin{array}{c}\text { Frequency } \\
(\%)\end{array}$ & $\begin{array}{c}\text { Cost of } \\
\text { management } \\
\text { (US\$) }\end{array}$ \\
\hline Hypertension & $125(66.4)$ & $1,413.1$ \\
\hline Neuropathy & $74(32.7)^{\prime}$ & $2,199.4$ \\
\hline Diabetic foot ulcer & $40(17.7)$ & $33,685.0$ \\
\hline Dyslipidemia & 32 (14.2) & 846.2 \\
\hline Chronic Renal Failure & $31(13.7)$ & $9,836.8$ \\
\hline Lung disease & $25(11.1)$ & 741.1 \\
\hline $\begin{array}{l}\text { Cerebrovascular } \\
\text { disease(stroke) }\end{array}$ & $13(5.7)$ & $4,230.3$ \\
\hline $\begin{array}{l}\text { Cardiovascular disease } \\
\text { (HHDX) }\end{array}$ & $13(5.7)$ & $1,782.0$ \\
\hline Liver diseases & $8(3.5)$ & 923.6 \\
\hline Retinopathy & $6(2.7)$ & 756.0 \\
\hline $\begin{array}{l}\text { Congestive heart } \\
\text { failure }\end{array}$ & $6(2.7)$ & 73.1 \\
\hline $\begin{array}{l}\text { Peptic ulcer disease } \\
\text { and bleeding }\end{array}$ & $6(2.7)$ & $1,148.0$ \\
\hline Total & & $47,798.1$ \\
\hline
\end{tabular}

The cost of management of the complications was $32.5 \%$ of the total cost of management. The cost related to foot care included dressing of ulcer/wound for the 40 patients and amputation for the 24 patients (US\$11,251.5), control of the blood glucose $(\$ 15,933.9)$ and use of antibiotics (US $\$ 6,441)$ was US $\$ 33,626.4$, which was an average of US $\$ 842.1$ per patient. The cost of management of DM foot was $22.1 \%$ of the total Cost-of-Illness (COI) for the 226 patients. The cost of management of chronic renal failure (CKD) among the 31 patients was estimated to be US\$6,327.2, giving an average of US\$204.1 per patient. The patients managed for CKD had some other costs of management added to their cost items. These included cost of anaemia, electrolyte imbalances, dialysis, and laboratory investigations related to the disease. The cost of management of retinopathy of 6 patients was US\$754.7 and average of US\$125.8 per patient.

The numbers of comorbid diseases was found to increase with increase in ages of patients (Pearson product moment correlation $r=0.3, p=$ $0.00)$. Duration of hospitalization increase with increase in number of comorbid disease (Pearson product moment correlation $r=0.13 p$ $=0.05$ ).
Cost of management also increased with increase in days of admission $(r=0.2, p=0.00)$, cost of laboratory investigation increased with increase in the number of comorbidities $(r=0.2$, $p=0.02$ ). Cost of management was found to increase with increase in comorbid diseases (Pearson product moment correlation $r=0.24, p$ $=0.00$ ).

\section{DISCUSSION}

Diabetes has been shown to exert a heavy economic burden on patients, national health system and society at large, and the burden borne depends on the differences in the socioeconomic status, and social insurance policies of the countries the patient live in [10]. Nigeria currently has a health insurance scheme (National Health Insurance Scheme -NHIS), which mainly services civil servants in the country and few members of the private sector [17]. Although the scheme has put measures in place to extend its service to the informal sector of social health insurance programme, which includes rural dwellers, artisans and other people/community who are not public servants or uniformed officers, few people are enrolled in it.

In this study, the majority of the patients paid for healthcare out-of-pocket. Because they did not enroll with the NHIS, they privately funded their health care. This is supported by a previous study in Nigeria which reported that more than $90 \%$ of patients privately fund their healthcare bills [18]. Furthermore, the findings of this study support previous research which reported that patients diagnosed with and being managed for diabetes in low-income countries like Nigeria are responsible for payment of the bulk of their healthcare cost (out-of-pockets) because there are no financial risk protection mechanisms [19]. This implies that diabetes exerts a heavy economic burden on the patients and their relations, who have to help out in making funds available for the management of the condition. The need for more enlightenment of the public on the National Health Insurance Scheme, especially the informal sector, which will bring about a co-payment design and reduce patient's out-of-pocket payment, is highly essential.

Non-adherence to medication(s) has been shown to be responsible for 33 to $69 \%$ of medicationrelated hospital admissions in the US [8]. This is similar to the finding in this study, because more than one-third of the patients diagnosed with type 2 diabetes hospitalized during the period of study were due to non-adherence. 
Table 3: Cost of hospitalization of patients for the 3-year period studied

\begin{tabular}{|c|c|c|c|c|c|c|}
\hline Cost variable & $\begin{array}{c}\text { Year of } \\
\text { admission }\end{array}$ & $\begin{array}{c}\text { Number of } \\
\text { patients }\end{array}$ & Amount (\$) & Total (\$) & $\begin{array}{c}\text { Mean cost/year } \\
\text { (US\$) }\end{array}$ & $\begin{array}{c}\text { Percent of } \\
\text { total cost (\%) }\end{array}$ \\
\hline Other drugs ( for & 2015 & 75 & $15,962.5$ & $40,204.9$ & 193.5 & 27.4 \\
\hline \multirow[t]{2}{*}{ Complications) } & 2014 & 68 & $11,997.4$ & & 178.3 & \\
\hline & 2013 & 83 & $12,244.9$ & & 162.0 & \\
\hline \multirow[t]{3}{*}{ Diabetes medications } & 2015 & 75 & $3,065.8$ & $10,094.1$ & 37.2 & 6.9 \\
\hline & 2014 & 68 & $3,028.3$ & & 45.0 & \\
\hline & 2013 & 83 & $4,000.0$ & & 52.9 & \\
\hline \multirow[t]{3}{*}{ Anti hypertensives } & 2015 & 75 & 303.1 & $1,410.7$ & 3.7 & 9.6 \\
\hline & 2014 & 68 & 555.6 & & 8.3 & \\
\hline & 2013 & 82 & 552.0 & & 6.1 & \\
\hline Total for all medications & & & & $51,709.7$ & 227.6 & 35.1 \\
\hline \multirow[t]{3}{*}{ Laboratory fee } & 2015 & 75 & $15,923.3$ & $42,247.1$ & 193.0 & 28.8 \\
\hline & 2014 & 68 & $12,269.2$ & & 182.3 & \\
\hline & 2013 & 83 & $14,054.7$ & & 185.9 & \\
\hline \multirow[t]{3}{*}{ Bed fee } & 2015 & 75 & $5,913.9$ & $15,553.0$ & 71.7 & 10.6 \\
\hline & 2014 & 68 & $4,039.6$ & & 60.0 & \\
\hline & 2013 & 83 & $5,599.5$ & $14,118.2$ & 74.1 & \\
\hline \multirow[t]{3}{*}{ Diabetes Diet } & 2015 & 75 & $5,390.6$ & & 65.3 & 9.1 \\
\hline & 2014 & 68 & $3,609.4$ & & 53.6 & \\
\hline & 2013 & 83 & $5,118.2$ & & 67.7 & \\
\hline \multirow[t]{3}{*}{ Consumables } & 2015 & 75 & $2,354.5$ & $7,514.6$ & 28.5 & 5.1 \\
\hline & 2014 & 68 & $2,337.0$ & & 34.7 & \\
\hline & 2013 & 83 & $2,823.1$ & & 30.9 & \\
\hline \multirow[t]{3}{*}{ Transportation fee } & 2015 & 75 & 741.0 & $1,463.9$ & 9.0 & 1.0 \\
\hline & 2014 & 68 & 307.3 & & 4.6 & \\
\hline & 2013 & 83 & 415.6 & & 5.5 & \\
\hline Blood Transfusion & 2015 & 4 & 186.3 & 651.9 & 42.3 & 0.4 \\
\hline \multirow[t]{2}{*}{$(\mathrm{N}=12)$} & 2014 & 2 & 139.7 & & 70.6 & \\
\hline & 2013 & 6 & 326.0 & & 59.6 & \\
\hline Wound care & 2015 & 17 & 855.6 & $1,880.1$ & 45.8 & 1.2 \\
\hline \multirow{2}{*}{$(\mathrm{N}=40)$} & 2014 & 8 & 346.3 & & 43.8 & \\
\hline & 2013 & 15 & 678.1 & & 46.5 & \\
\hline Use of Oxygen & 2015 & 6 & 122.2 & 646.1 & 18.5 & 0.4 \\
\hline \multirow{2}{*}{$(\mathrm{N}=29)$} & 2014 & 11 & 197.9 & & 18.2 & \\
\hline & 2013 & 12 & 326.0 & & 29.8 & \\
\hline Amputation & 2015 & 9 & 4.190 .9 & 9371.4 & 423.3 & 6.4 \\
\hline \multirow{2}{*}{$(\mathrm{N}=24)$} & 2014 & 8 & $2,328.3$ & & 470.6 & \\
\hline & 2013 & 7 & $2,852.2$ & 465.7 & 446.9 & \\
\hline Other procedures & 2015 & 1 & 232.8 & & 211.6 & 0.3 \\
\hline$(\mathrm{N}=2)$ & 2014 & 1 & 232.8 & & 235.3 & \\
\hline Physiotherapy service & 2015 & 3 & 43.7 & 116.4 & 13.2 & \\
\hline \multirow[t]{2}{*}{$(\mathrm{N}=7)$} & 2014 & 2 & 29.1 & & 14.7 & \\
\hline & 2013 & 3 & 43.7 & & 16.0 & 0.08 \\
\hline \multirow[t]{4}{*}{ Total } & 2015 & 75 & $55,286.2$ & & & \\
\hline & 2014 & 68 & $41,417.9$ & & & \\
\hline & 2013 & 83 & $49,034.0$ & & & \\
\hline & & 226 & $145,738.1$ & $145,738.1$ & 650.1 & \\
\hline
\end{tabular}

Exchange rate for the three years was 171.8 to US\$1

The cost of hospitalization resulting from nonadherence to medication(s) among the studied population was high considering the fact that the expenditures of majority of these patients were out-of-pocket. In addition, most of these patients were from the low socioeconomic class comprising petty traders, retired workers, artisans and the unemployed, who have been shown in past studies in the same healthcare facility to have meagre income $[14,18]$ and are, therefore, not financially strong to cope with the cost of their medications. Cost of medications has been reported to be a strong reason for non- adherence to medication(s) among the studied population [18].

In a previous study on cost of hospitalization of diabetes patients, laboratory costs rated highest when compared to other costs, like cost of medications [20]. In this study, cost of medications, both for diabetes and other comorbid conditions, accounted for the highest cost. Cost of laboratory investigations on the course of admission was one third of the total expenditure. Cost of laboratory investigation was found to increase with increase in the number of 
comorbid diseases. Some of these investigations would not have been recommended if the patient had adhered to the recommended medications and had not developed complication(s). Cost of other drugs used in the management of complications of DM was found to be more than one-quarter of the total cost of management on admission (Table 3). In addition, cost of other management attributed to the hospitalization resulting from the non-adherent behaviour of patient was high.

The average $\mathrm{HbA1c}$ (which was far higher than the normal value of $<7.0 \%$ ) at admission showed that the patients were not adherent to their medication(s). A previous study showed that haemoglobin $A 1 C$ reduces with increase in adherence to diabetes medications use [21]. Besides, many of them would have developed complications before they were admitted, which also increases the cost of management. Cardiovascular complications tend to increase with increase in $1.0 \%$ of $\mathrm{HbA} 1 \mathrm{c}$ above normal or target level of $7.0 \%$ [22]. The increase in comorbid disease with age has been reported [23] and this becomes worse in patients with poor clinical outcome (high HbA1c) who are in their advanced age and do not adhere to their medications.

Diabetic neuropathy was the most common complication among the participants but the cost of managing it was not as high as those with Diabetes Foot Ulcer (DFU). However, all the patients in this study with DFU also presented with diabetic neuropathy -a major risk factor for DM foot ulceration [24]. Cost was higher among patients managed for DFU as compared to other complications of DM. The average cost of managing DM foot in this study was found to be a little lower than $\$ 180,581.6$ (\$1051.1), which was reported in a previous study in Nigeria [24]. More than two-thirds of the DFU patients in that study had amputation, which accounted for the increase in the cost of management [24] compared to this study, where more than half of the DFU patients underwent amputation while on admission.

Another complication which invariably increased cost of management among the patients was chronic renal failure. However, the prevalence among the studied population was lower than the $11 \%$ reported in a previous study in a hospital setting in Nigeria [25].

\section{Limitations of the study}

This was a retrospective study. There was no direct contact with the patients to establish report of medication non-adherence and reason(s) for their non-adherence to medication. The study relied on the accuracy and completeness of physician's subjective assessment of patients for non-adherence to medication(s) made available in the patients' case notes. There could have been some patients among those admitted that would have been missed out in the process of assessing their adherence to medication(s). Therefore, cost of hospitalization may be much higher than what was reported in the study. In addition, indirect costs (such as, mortality, caregivers, and productivity loss) on the parts of the patients and caregivers were not accounted for in this study, which would have increased the cost associated with hospitalization.

\section{CONCLUSION}

The cost of hospitalization associated with nonadherence to medication(s) for patients with T2DM is huge (average of \$650.0), an amount too large for an individual in a country where a substantial number of its citizens live on $<\$ 57$ monthly. It is suggested that healthcare providers and health policymakers should focus on factors associated with non-adherence among patients with the aim of resolving it through a proven intervention programme in order to reduce the cost associated with it.

\section{DECLARATIONS}

\section{Acknowledgement}

The authors acknowledge members of medical records unit of University College Hospital, Ibadan, Nigeria who assisted in making available the medical records of patients. This research received no specific grant from any funding agency in the public, commercial, or not-for-profit sectors.

\section{Conflict of Interest}

No conflict of interest associated with this work.

\section{Contribution of Authors}

The authors declare that this work was done by the authors named in this article and all liabilities pertaining to claims relating to the content of this article will be borne by them.

\section{Open Access}

This is an Open Access article that uses a funding model which does not charge readers or their institutions for access and distributed under 
the terms of the Creative Commons Attribution License (http://creativecommons.org/licenses/by/ 4.0) and the Budapest Open Access Initiative (http://www.budapestopenaccessinitiative.org/rea d), which permit unrestricted use, distribution, and reproduction in any medium, provided the original work is properly credited.

\section{REFERENCES}

1. Adeloye $D$, Ige JO, Aderemi AV, Adeleye N, Amoo EO, Auta A, Oni G. Estimating the prevalence, hospitalization and mortality from type 2 diabetes mellitus in Nigeria: a systematic review and metaanalysis. BMJ Open 2017; 7:e015424. doi:10.1136/ bmjopen-2016-015424.1-16

2. Bilikis $B$. Reducing prevalence of diabetes mellitus. http://www.bussinessdayonline.com/NG/index.php/analy sis/commentary/47930-reducingprevalence- of-diabetesm. Accessed 27 December 2017.

3. Akinkugbe OO. Non-communicable diseases in Nigeria: national survey (Final Report) on hypertension, coronary heart disease, diabetes mellitus, haemoglobinopathies, G6PD deficiency and anaemia. Lagos: Federal Ministry of Health and Social Services - National Expert Committee on Non-Communicable Diseases, 1997.

4. Ogbera AO, Ekpebegh C. Diabetes mellitus in Nigeria: the past, present and future. W J Diabetes 2014; 5 : 905-11.

5. Egede LE, Gebregziabher $M$, Dismuke CE, Lynch CP, Axon NR, Zhao $Y$, Mauldin $P D$. Medication non adherence in diabetes: Longitudinal effects on costs and potential cost savings from improvement. Diabetes Care. 2012; 35 (12): 2533-2539.

6. Polonsky WH, Henry RR. Poor medication adherence in type 2 diabetes: recognizing the scope of the problem and its key contributors. Patient Preference Adherence. 2016; 10: 1299-1307. doi: 10.2147/PPA.S106821 PMCID: PMC4966497. Assessed 16th March, 2018.

7. McCarthy $R$. The price you pay for the drug not taken. Bus Health 1998; 16: 27-33.

8. Osterberg L, Blaschke T. Adherence to medication. $N$ Engl J Med 2005; 353: 487-497

9. Salas $M$, Hughes $D$, Zuluaga $A$, Vardeva $K$, Lebmeier $M$. Costs of medication non adherence in patients with diabetes mellitus: a systematic review and critical analysis of the literature. Value Health 2009; 12: 915 922.

10. Zhang P, Zhang X, Brown J, Vistisen D, Sicree R, Shaw $J$, Nichols G. Global healthcare expenditure on diabetes for 2010 and 2030. Diabetes Res Clin Pract 2010; 87: 293-301.

11. Odegard PS, Gray SL. Barriers to medication adherence in poorly controlled diabetes mellitus. Diabetes Educ 2008; 34: 692-697.
12. WHO. 2016. Global report on diabetes. Available on http://www.who.int. Assessed on 16 March, 2018.

13. Okoronkwo IL, Ekpemiro JN, Okwor EU, Okpala, PU, Adeyemo FO. Economic burden and catastrophic cost among people living with type 2 diabetes mellitus attending a tertiary health institution in south [east zone, Nigeria. BMC Research Notes 2015; 8:527. DOI 10.1186/s13104-015-1489-x. Assessed 22 December, 2017.

14. Ipingbemi $A E$, Erhun WO. Cost implications of treatment of diabetes mellitus in a secondary healthcare facility in Ibadan. Afr J Med med Sci 2015; 44: 79-87.

15. https://www.ecfr.gov/cgibin/retrieveECFR?gp $=\& S I D=83 \mathrm{c}$ d09e1c0f5c6937cd9d7513160fc3f\&pitd $=20180719 \& n=p t$ 45.1.46\&r=PART\&ty=HTML. Assessed 29 January, 2019.

16. https://www.oanda.com/currency/converter/ Assessed on 3 July, 2018.

17. National Health Insurance Scheme https://www.nhis. gov.ng/ Assessed 18 December, 2017.

18. Enwere OO, Salako, BL, Falade CO. Prescription and Cost Consideration at a Diabetic Clinic in Ibadan, Nigeria: A Report. Ann Ibadan Postgraduate Med 2006; 4 (2): 35-39

19. Ichoku HE, Eme H, Fonta WM, Onwujekwe OE. Incidence and intensity of catastrophic healthcare financing and impoverishment due to out-of-Pocket payments in Southeast Nigeria. J Insurance Risk Management 2009; 4(4): 47-59.

20. Odili UV, Okwuanasor E. Estimating the Cost of Diabetes Hospitalization in a Secondary Health Care Facility. Nigerian J Pharm Sci 2011; 11 (1): 49-57.

21. U.S. Department of Veterans Affairs. VA/DoD clinical practice guideline for the management of diabetes [Internet], 2011. Available from http://www.healthquality. va.gov/diabetes/DM2010_FUL-v4e.pdf. Assessed 12 February, 2017.

22. Kranenburg $G$, van der Graaf $Y$, van der Leeuw J, Nathoe HM, de Borst GJ, Kappelle LJ, Visseren FL, Westerink J, SMART Study Group. The Relation between HbA1c and Cardiovascular Events in Patients with Type 2 Diabetes with and without vascular disease. Diabetes care 2015; 38(10): 1930-1936.

23. Davis JW, Chung R, Juarez DFT. Prevalence of Comorbid Conditions with Aging among Patients with Diabetes and Cardiovascular Disease. Hawaii Med J 2011; (70)10: 209-213.

24. Ogbera AO, Fasanmade O, Ohwovoriole AE, Adediran $O$. An assessment of the disease burden of foot ulcers in patients with diabetes mellitus attending a teaching hospital in Lagos, Nigeria. Int J Low Extremities Wounds 2006; 5 (4): 244-249.

25. Umuerri EM, Obasohan AO. Lower extremity peripheral artery disease: prevalence and risk factors among adult Nigerians with diabetes mellitus. W Afr J Med 2013; 32 (3): 200-205. 